\title{
Análise de uma sequência didática para o estudo em Ictiologia por meio de ludicidade e metodologias ativas com base na BNCC e na abordagem CTSA
}

\author{
Analysis of a didactic sequence in a study on Ichthyology through playfulness and active \\ methodologies based on the BNCC and the CTES approach \\ Análisis de una secuencia didáctica en un estudio sobre Ictiología a través de la lúdica y \\ metodologías activas basadas en el enfoque BNCC y CTSA
}

Recebido: 06/10/2021 | Revisado: 12/10/2021 | Aceito: 21/10/2021 | Publicado: 23/10/2021
Kévila Kelma Nascimento Silva dos Passos ORCID: https://orcid.org/0000-0001-9265-0622 Universidade Federal de Itajubá, Brasil E-mail: kevilakelma@gmail.com
Milady Renata Apolinário da Silva ORCID: https://orcid.org/0000-0002-0496-2085 Universidade Federal de Itajubá, Brasil E-mail: milady@unifei.edu.br

\begin{abstract}
Resumo
Para os docentes, que recentemente tem atuado de maneira remota ou com no ensino híbrido, a sequência didática vem com uma ferramenta de auxílio. A sequência didática (SD) não é uma substituição aos planos de aulas, uma vez que estes são obrigatórios mas auxilia o professor na organização e no atendimento aos objetivos de suas aulas. Desta forma, neste trabalho foi desenvolvido uma sequência didática para o ensino de ciências, mais precisamente em Ictiologia, e sua análise foi feita com base na abordagem CTSA e nas BNCC, estabelecida para os Anos Iniciais do Ensino Fundamental. Inicialmente, esta sequência foi feita para ser aplicada no Ensino de Ciências, tendo como contexto um Projeto de Aquaponia que seria desenvolvido no Centro de Apoio Nossa Senhora do Sagrado Coração (CANSCC) em Itajubá-MG, dando ênfase aos vertebrados e à ictiologia. Esta SD foi desenvolvida no ano de 2020, associada ao Projeto Semeando Cientistas da Universidade Federal de Itajubá (UNIFEI) com subsídio da Pró-Reitoria de Extensão (PROEX-UNIFEI). Espera-se desta sequência didática em função da BNCC, que a aplicação de metodologias ativas, como histórias e jogos, além de recursos como dança e o uso da ludicidade tende a auxiliar positivamente no processo ensino-aprendizagem de Ciências. A abordagem CTSA na sequência didática, resulta na formação cidadã de indivíduos críticos, capazes de promoverem uma ação sustentável para preservação do meio ambiente, em uma sociedade harmoniosa, que respeita valores e as diferenças.
\end{abstract}

Palavras-chave: BNCC; Ictiologia; CTSA; Ludicidade; Metodologias ativas.

\begin{abstract}
For teachers, who have recently been working remotely or with hybrid teaching, the didactic sequence comes with an support tool. The didactic sequence (DS) is not a replacement for lesson plans, as these are mandatory, but it helps the teacher in organizing and meeting the objectives of their classes. Thus, in this work, a didactic sequence for the teaching of science was developed, more precisely in Ichthyology, and its analysis was made based on the CTSA approach and the BNCC, established for the Early Years of Elementary School. Initially, this sequence was made to be applied in Science Teaching, within the context of an Aquaponics Project that would be developed at the Nossa Senhora do Sagrado Coração Support Center (CANSCC) in Itajubá-MG, with emphasis on vertebrates and ichthyology. This DS was developed in 2020, associated with the Semeando Cientistas Project at the Federal University of Itajubá (UNIFEI) with a subsidy from the Pro-Rectory of Extension (PROEX-UNIFEI). It is expected from this didactic sequence, due to the BNCC, that the application of active methodologies, such as stories and games, as well as resources such as dance and the use of playfulness, tends to help positively in the teaching-learning process of Science. The CTES approach, in the didactic sequence, results in the civic education of critical individuals, capable of promoting a sustainable action to preserve the environment, in a harmonious society, which respects values and differences.
\end{abstract}

Keywords: BNCC; Ichthyology; CTES; Playfulness; Active methodologies.

\section{Resumen}

Para los profesores que han estado trabajando recientemente de forma remota o con la enseñanza híbrida, la secuencia didáctica viene con una herramienta de ayuda. La secuencia didáctica (SD) no sustituye a los planes de estudio, ya que son obligatorios, pero ayuda al profesor a organizar y cumplir los objetivos de sus clases. Así, en este trabajo se 
desarrolló una secuencia didáctica para la enseñanza de las ciencias, más precisamente en Ictiología, y su análisis se realizó con base en el enfoque CTSA y el BNCC, para el grupo de edad establecido en los Primeros Años de Educación Primaria. Inicialmente, esta secuencia se hizo para ser aplicada en la Enseñanza de las Ciencias, en el contexto de un Proyecto de Acuaponía que se desarrollaría en el Centro de Apoyo Nossa Senhora do Sagrado Coração (CANSCC) en Itajubá-MG, con énfasis en vertebrados e ictiología. Este SD fue desarrollado en 2020, asociado al Proyecto Semeando Cientistas de la Universidad Federal de Itajubá (UNIFEI) con un subsidio de la Pro-Rectoría de Extensión (PROEX-UNIFEI). Se espera de esta secuencia didáctica, debido al BNCC, que la aplicación de metodologías activas, como cuentos y juegos, así como recursos como la danza y el uso de la alegría, tiende a ayudar positivamente en el proceso de enseñanza-aprendizaje de Ciencias. El enfoque de la CTSA, en la secuencia didáctica, resulta en la educación cívica de individuos críticos, capaces de promover una acción sostenible para preservar el medio ambiente, en una sociedad armoniosa, que respeta los valores y las diferencias.

Palabras clave: BNCC; Ictiología; CTSA; Alegría; Metodologías activas.

\title{
1. Introdução
}

O ensino de ciências se apresenta essencial na vida de cada aluno. Isto pode ser mais verificado durante a pandemia, onde o conhecimento científico tem tentado se sustentar mediante a tantas informações aleatórias, e muitas vezes sem fundamentos, com uma carência de embasamentos ante a um sociedade que busca por interesses comuns, um tanto supérfluos e sua inspiração em notícias falsas e com baixo teor científico. Nesse momento, que há um confronto entre o conhecimento científico e conhecimentos populares ou notícias falsas, o docente entra como um mediador para apresentar fundamentos científicos concretos e estabelecer a ligação entre o conhecimento fundamentado, para que assuntos como saúde, por exemplo, sejam explicados de maneira científica, adequada e acessível.

Para o desenvolvimento do aluno é importante um ensino de ciências, para além da aprendizagem a relacionar situações e fenômenos de seu cotidiano, permita a associação do objeto do conhecimento com situações e suas vivências, proporcionando para o mesmo experiências científicas tanto teóricas quanto práticas, que poderão resultar em uma aprendizagem significativa. De acordo com Kurz, Bedin \& Groenwald (2020, p.12):

\begin{abstract}
Ademais, atenta-se que nesta etapa de ensino deve-se promover o acesso a diversidade do conhecimento científico, com o intuito de propiciar o primeiro contato com assuntos relativos a Ciências não especificamente às questões voltadas ao ensino de Biologia, mas as manifestações dos fenômenos naturais. Este deve ocorrer de formas gradativa e processual, por meio de propostas que possibilitam aos estudantes vivenciarem os processos de investigação, observação, análise, discussão e socialização das ideias. Ainda, e tampouco, cabe ao professor não se deter com a precisão e a sistematização rigorosa de conceitos, visto que este movimento consiste em um processo constante de construção e de reconstrução dos significados atribuídos a um determinado fenômeno. (Kurz, Bedin \& Groenwald, 2020, p.12)
\end{abstract}

Atualmente, principalmente devido ao Ensino Remoto, muitas metodologias têm sido aplicadas. Em conformidade, os autores Bacich \& Moran (2018) discorrem a eficiência de metodologias ativas no Ensino de Ciências e que estas podem colaborar para o desenvolvimento cognitivo de alunos, como elaborar modelos, colocar o conhecimento na prática, investigação, experimentos e o uso de tecnologias. "A aprendizagem é mais significativa quando motivamos os alunos intimamente, quando eles acham sentido nas atividades que propomos, quando consultamos suas motivações profundas, quando se engajam em projetos para os quais trazem contribuições, quando há diálogo sobre as atividades e a forma de realizá-

las." (Bacich \& Moran, 2018, p.1)

Metodologias ativas são estratégias de ensino centradas na participação efetiva dos estudantes na construção do processo de aprendizagem, de forma flexível, interligada e hibrida. As metodologias ativas, num mundo conectado e digital, expressam-se por meio de modelos de ensino híbridos, com muitas possíveis combinações. A junção de metodologias ativas com modelos flexíveis e híbridos traz contribuições importantes para o desenho de soluções atuais para os aprendizes de hoje. (Bacich \& Moran, 2018, p.2) 
O uso da ludicidade também pode colaborar para o desenvolvimento social e interativo do aluno. Em um momento de pandemia em que alunos estão em suas casas, geralmente somente com o convívio dos familiares, quase nunca vendo seus colegas da escola, as crianças tendem a crescer com certos traumas e se introverterem. Para isso, tal Santos, Miranda \& DeCarvalho (2021, p.186) afirmam: "Práticas lúdicas, quando inseridas no planejamento escolar com finalidades específicas, podem colaborar para o desenvolvimento de múltiplas habilidades no educando, estreitar a construção de laços afetivos, melhorar as interações socioculturais e ampliar a capacidade psicocognitiva".

Um dos recurso que podem passar os tempos, mas que fica marcando na infância de qualquer pessoa são as histórias narradas. A maioria das pessoas pode parar por um instante, pensar e se lembrarão de histórias contadas e que fizeram parte de sua vida, além de brincadeiras e atividades. "As narrativas são elementos poderosos de motivação e produção de conhecimento. E importante utilizar narrativas, histórias, simulações, imersões e contos de fantasia sempre que possível, com ou sem recursos tecnológicos (p. ex., tribunal de juri)" (Bacich \& Moran, 2018)

Porém o uso da ludicidade, embora eficaz e atraente, pode demandar tempo do educador. Exige um planejamento da parte dele, tal qual, a verificação das necessidades dos alunos, disponibilizar algum momento da semana para desenvolver as atividades, construir jogos, criatividade o que também exige recursos financeiros, que muitas vezes sairá a seu encargo, visto de muitos dos jogos disponíveis da escola, podem não ser adequados aos alunos e ao ambiente que convivem. (Moro \& Carlesso, 2020, p.338).

Para os docentes, que recentemente tem atuado de maneira remota ou com o ensino híbrido, a sequência didática vem com uma ferramenta de auxílio, tanto no ensino presencial quanto no ensino remoto. Muitos desses professores sobrecarregados de afazeres, como na região de Minas Gerais, com o Regime Especial de Atividades Não Presenciais (REANP); com o preenchimento do Sistema Mineiro de Avaliação e Equidade da Educação Público (SIMAVE); bem como o Diário Eletrônico, além do recebimento de PETs em suas casas por meio dos envio nos e-mails, e no conexão escola, podem sofrer a dificuldade de ainda ter que fazer seus planos de aula. (Minas Gerais, 2021, p.2)

Para tais efeitos, entra a sequência didática, que não vem para substituir os planos de aulas, uma vez que estes são obrigatórios. Elas vem para incrementar as aulas visto que, estas podem ser modificadas e adaptadas para os alunos, o ambiente inserido e para a quantidade de aulas a serem ministradas, pode-se também mudar os métodos empregados, inserir outros que de acordo com a situação serão melhor empregados e adequados para os alunos onde ela será aplicada.

E quando falamos de sequência didática, não podemos deixar de descrever o que elas são, e como elas se desenvolvem. Um dos autores mais utilizados para apresentá-las consiste em Antoni Zabala (1998), que embora seja da década de 90, as metodologias aplicadas ainda funcionam.

De acordo com Zabala (1998, p.56), para que a sequência didática seja produzida, alguns elementos podem ser fundamentais e condições a ela associadas, como ambiente aonde ela será aplicada e o perfil dos alunos. A destacar novamente, que esta se diferencia de um plano de aula, onde ele possui um esquema padrão e imutável, já sistematizado. Para que haja o desenvolvimento de uma sequência didática, precisa-se construir alguns processos, para um resultado satisfatório. Para tal, na Unidade 1, ele apresenta estes "cinco passos": A Comunicação da lição, que seria a interação do professor com alunos para compreender quais são os conhecimentos prévios e experiências pessoais dos mesmos; o Estudo individual sobre o livro-texto, onde se apresenta aos alunos o Conhecimento científico; a Repetição do conteúdo aprendido, momento em que o professor estabelece atividades, de modo reiterado; Prova ou exame, o uso de avaliações pra que o aluno aplique o que ele aprendeu; e no final, a Avaliação da Sequência, onde apresenta-se as resultâncias do aprendizagem do aluno, mediante ao objetivo estabelecido.

Dados os fatos, para a construção de uma Sequência Didática eficaz, deve-se também alinhar-se aos parâmetros curriculares, com as habilidades e competências contidas na a Base Nacional Comum Curricular (BNCC). Por sua vez, ela 
instiga a elaboração de materiais didáticos baseados nas Competências Gerais da educação Básica e para o Ensino de Ciências podemos abordar:

Exercitar a curiosidade intelectual e recorrer à abordagem própria das ciências, incluindo a investigação, a reflexão, a análise crítica, a imaginação e a criatividade, para investigar causas, elaborar e testar hipóteses, formular e resolver problemas e criar soluções (inclusive tecnológicas) com base nos conhecimentos das diferentes áreas. (BNCC, 2018, p.9)

Ela também contempla a utilização de diferentes linguagens para se expressar e compartilhar informações, experiências, ideias e sentimentos em contextos distintos e motivando os sentidos para uma melhor compreensão mútua dos diversos conhecimentos, das linguagens artística, matemática e científica, por meio da: da linguagem verbal (oral ou visual-motora, como Libras, e escrita), corporal, visual, sonora e digital, como facilitadores da aprendizagem.

Mediante a tantos dados, não se pode deixar de citar a importância de tais agentes, porém associados à uma abordagem adequada. Quando se envolve a sociedade e o meio ambiente, na formação de indivíduas críticos, a utilização pode-se efetuar por meio a de uma abordagem CTS ou CTSA (esta por sua vez é mais ampla). Para compreender, o autor argumenta Almeida et. al (2021, p.98):

A abordagem CTSA assume a prioridade da aprendizagem de temas relevantes, não só para o aluno, mas também para a sociedade, bem como a aprendizagem dos conceitos científicos a partir de exemplos do dia-a-dia, tornando a ciência, não só mais motivante, mas também mais útil, e o ensino mais contextualizado e atual. (Almeida et. al, 2021, p.98)

Para Fernandes \& Pires (2019) essa abordagem precisa superar o currículo, promovendo uma ação humana que conscientize sobre questões problemáticas, relacionadas a formação cidadã quanto a ação da sociedade, bem como o homem, sobre o meio ambiente, com soluções de problemas incrementando um modelo sustentável:

Mas para implementar a educação CTSA no ensino das ciências, capaz de promover nos alunos a literacia científica, é necessário que os currículos de ciências proponham o desenvolvimento de processos científicos (observar, inferir, classificar, explicar, relacionar, argumentar), a resolução de problemas e a melhoria do pensamento crítico; fomentem o desenvolvimento de princípios e normas de conduta responsáveis e conscientes, individuais e coletivos; promovam o desenvolvimento de decisões conscientes, informadas e argumentadas face às consequências da ação humana no ambiente, bem como o envolvimento do aluno em questões problemáticas atuais relacionadas com a cidadania, a sustentabilidade e a proteção do ambiente. (Fernandes \& Pires, 2019, seção Porquê ensinar ciência?)

O objetivo do presente trabalho é analisar o desenvolvimento de uma sequência didática baseada na abordagem CTSA, com base na faixa etária estabelecida dos Anos Iniciais do Ensino Fundamental, adequando às faixas etárias de 9 a 10 anos. Consiste em verificar a adequação de uma sequência didática ao Ensino de Ciências, para o "Projeto de Aquaponia" no Centro de Apoio do Sagrado Coração, na introdução do estudo dos vertebrados e ictiologia, com base na BNCC e na abordagem CTSA.

\section{Metodologia}

Esta Sequência didática foi desenvolvida no ano de 2020, associada ao Projeto Semeando Cientistas da Universidade Federal de Itajubá (UNIFEI) com subsídio da Pró-reitora de Extensão (PROEX) desta instituição. Este Projeto tem por objetivo oferecer o empoderamento de crianças carentes, onde muitas dessas crianças apresentam situação de vulnerabilidades socioeconômicas. Para tais, o projeto é aplicado no Centro de Apoio Nossa Senhora do Sagrado Coração, (popularmente conhecido como Granja) em Itajubá-MG.

O Centro de Apoio é uma Instituição sem fins lucrativos fundada em 1948, antigamente o regime era de abrigo, hoje com objetivo de acolher e amparar menores carentes da cidade de Itajubá. As crianças atendidas nessa organização é de 
aproximadamente 160 crianças e adolescentes, sendo estas entre 5 a 14 anos de idades. $O$ ambiente dispõe de ambiente natural ao ar livre e parquinho, espaços internos como sala de vídeo, sala de oficinas - para atividades como pintura em tela, artesanatos, entre outros; sala de informática, brinquedoteca, refeitório e por fim, cozinha (Prosas, 2021). Posto isto, além das atividades contraturnos do Centro de Apoio, o Projeto Semeando Cientistas emprega atividades de aulas de inglês, ciências, robótica, além de explanar sobre inteligência emocional, com o incentivo à liderança.

Dentro Projeto Semeando Cientistas, existe o escopo de trabalhar-se com a Aquaponia, por meio da Hidroponia e Piscicultura. Os alunos por sua vez, precisam conhecer conceitos científicos e pesando nisso, desenvolveu-se esta sequência didática (SD). O conteúdo dessa SD tem como base a Base Nacional Comum Curricular (BNCC), configurado aos Anos Iniciais do Ensino Fundamental, adequando-se aos $3^{\circ}$ e $4^{\circ}$ ano, contemplando as competências e habilidades, como podem ser visualizadas no Quadro 1. Além disso, a pesquisa consiste em um estudo de caso com parâmetros qualitativos (Pereira et al, 2018).

Quadro 1 - Competências da BNCC utilizadas para o Desenvolvimento da Sequência Didática.

\begin{tabular}{|c|c|c|}
\hline UNIDADES TEMÁTICAS & $\begin{array}{c}\text { OBJETOS DE } \\
\text { CONHECIMENTO }\end{array}$ & \multicolumn{1}{c|}{ HABILIDADES } \\
\hline Vida e evolução & $\begin{array}{c}\text { Características e } \\
\text { desenvolvimento dos animais }\end{array}$ & $\begin{array}{l}\text { (EF03CI04) Identificar características sobre o modo de vida } \\
\text { (o que comem, como se reproduzem, como se deslocam etc.) } \\
\text { dos animais mais comuns no ambiente próximo. } \\
\text { (EF03CI05) Descrever e comunicar as alterações que ocorrem } \\
\text { desde o nascimento em animais de diferentes meios terrestres } \\
\text { ou aquáticos, inclusive o homem. } \\
\text { (EF03CI06) Comparar alguns animais e organizar grupos com } \\
\text { base em características externas comuns (presença de penas, } \\
\text { pelos, escamas, bico, garras, antenas, patas etc). }\end{array}$ \\
\hline
\end{tabular}

Fonte: BNCC, 2018 (adaptado).

O principal tema a ser abordado em toda a sequência didática, como já previamente dito é ictiologia - estudos dos peixes, em específico, os de água doce. Sua interação fisiológica com a água, a morfologia, reprodução, alimentação, ciclo de vida e por fim, questões ambientais, que englobam a educação ambiental, sobretudo a poluição.

Para Maestrelli E Lorenzetti (2021, p.18), a abordagem CTSA, ocorre quando há educação ambiental crítica para a formação da cidadania, por meio de uma relação com o meio ambiente de modo ético. Destaca que esta relação precisa ser normativa, rotineira e reprodutiva, onde se envolva conhecimentos, valores, atitudes e habilidade com intuito na colaboração de mudança da realidade. Com base neste argumento, visou-se no decorrer na construção da SD tratar tais assuntos, tanto nas músicas e vídeos elaborados, para que as crianças entendessem a ação do homem sobre o meio ambiente.

Entre os momentos, existe sempre a proposta de aulas dialógicas, perguntando aos alunos sobre o que ele aprenderam das aulas anteriores e da atual. Também foi elaborada "A história de um peixe", que trata-se de um peixe que está com risco de Extinção, a Piaba, típica da Região do Cerrado, em Minas Gerais. Os alunos também desenvolvem atividades previamente estruturadas que envolve o conteúdo científico e crítico. Além disso, existe orientações aos docentes para que estas se desenvolvam ao modo de contemplar a metodologia CTSA, desenvolvendo a criticidade dos alunos e a observação do seu espaço com o meio ambiente. 
Embora a faixa etária seja os anos iniciais do Ensino Fundamental, a sequência didática também pode ser utilizada no Ensino Fundamental Anos Finais e no Ensino Médio, porém com ações investigativas, proposta de soluções-problemas, debates e outros experimentos, relatórios, oferecendo mais autonomia aos alunos para o senso crítico.

\section{Resultados e Discussão}

\subsection{Estrutura da Sequência Didática}

A orientação da sequência didática desenvolvida é a promoção de atividades que contribuam para o desenvolvimento dos alunos mediante o Projeto Semeando Cientistas, em específico, no projeto desenvolvido de Aquaponia, juntamente com o CANSSC - Granja. Para tal, para que o os alunos compreendam esse sistema de agricultura sintrópica associado a Aquaponia, em destaque a Piscicultura. É fundamental que os alunos compreendam os conceitos científicos sobre ictiologia - estudo sobre peixes, principalmente peixes de água doce. Faz-se aqui uma associação à região de Itajubá, por meio da história de uma Piaba -peixe de água doce comum na região de Minas Gerais- salienta-se a morfologia, reprodução, fisiologia, de maneira bem lúdica e adaptada à faixa etária dos alunos.

A sequência didática foi estruturada em 4 etapas, e apresenta uma quantidade total de 10 aulas (geralmente 50 minutos), algumas das atividades apresentadas podem ser repetidas pelo professor até a compreensão dos alunos sobre o assunto, sendo este usual em sequências didáticas, uma vez que são modificáveis. Tais aulas surgem dessa proposta em virtude da disponibilidade de aulas do professor, do ambiente em que está sendo aplicada e da realidade de cada aluno. Para tanto, tal desenvolvimento e estruturação da sequência é exibida no Quadro 2.

Quadro 2 - Estrutura da Sequência Didática para tratar o assunto de Ictiologia -Vertebrados e Aquaponia.

\begin{tabular}{|c|c|}
\hline Aula & Desenvolvimento das atividades \\
\hline $\begin{array}{l}\text { Aula 1: Apresentação da SD e } \\
\text { ideias iniciais }\end{array}$ & $\begin{array}{l}\text { Atividade 1: } \\
\text { Quantidade de aulas: } 2 \\
\text { Objetivo: } \\
\text { • Potencializar conhecimentos prévios sobre peixes; } \\
\text { Conteúdo Físico: Peixes - Vertebrados } \\
\text { Recurso: Televisão, Datashow ou folhas com figuras impressas; } \\
\text { Motivação: } \\
\text { Olá, gente! Vocês sabem aonde encontramos peixe? Vocês sabem porque eles nadam? Vocês sabem o } \\
\text { que eles comem? } \\
\quad \text { Momentos sugeridos entre as atividades } \\
\text { Momento 1: } \\
\text { Após o levantamento de questões prévias, exibe-se um vídeo que foi elaborado para o Projeto } \\
\text { Semeando Cientistas, “Água Doce, minha casa, minha vida!” } \\
\text { "Olá, gente! } \\
\text { Eu sou a Peixinha Juju! } \\
\text { Pra quem não sabe o que eu sou, eu sou uma Piaba! Minha espécie está em risco de extinção ou seja, } \\
\text { podemos um dia desaparecer porque somos muito caçados... Que triste né? } \\
\text { Sou um peixe de água doce! Pois é, peixe não nada somente do mar! existe peixes que nadam em rios } \\
\text { e lagos! } \\
\text { Eu nado aqui na Região do Cerrado, ele passa por Minas Gerais! } \\
\text { Pra ser sincera, toda a minha família veio do Rio Sapucai, que se encontra em Itajubá. Eu, meu papai, } \\
\text { minha mamãe e meus irmãozinhos. } \\
\text { Eu quando nasci, nasci de pequenos ovos... isso! Minha mãe é ovípara... Ela conheceu meu pai, pois } \\
\text { ele a amava muito e a respeitava, depois diz minha mãe, que eles tiveram a gente. }\end{array}$ \\
\hline
\end{tabular}


Eu tinha formato de ovinho, depois uma larvinha e que depois foi crescendo, crescendo e crescendo... até se torna isso que sou hoje! Uma peixinha linda e charmosa, haha... vocês não concordam, não é? Meu corpo é cheia de escamas, alguns peixes são formados com couro, como a minha amiga tal. Me alimento de plantas e tem peixes que comem outros peixes (eu tenho medo deles, pois eu tenho que fugir deles!)

Mas como faço para respirar de baixo de água?

Enquanto vocês humanos tem pulmões, ou tenho brânquias que me ajudam a viver debaixo da água. E para me movimentar, eu uso minhas barbatanas e nadadeiras!

Geralmente os peixes de água doce, fazem muito xixi que contém 3 elementos básicos: amônia, nitrito e nitrato. Ele favorecem a respiração e auxiliam as plantas na fotossíntese.

Nós fazemos xixi no mesmo lugar que respiramos... Você deve estar falando agora: uhhh, que nojo! Mas para os peixes é uma coisa normal, já que não temos como sair da água para fazer isso!

Mas viver debaixo da água é muito bom! É emocionante... exceto quando os seres humanos jogam lixo nos rios e os esgoto estraga a água em que vivemos. Como respiramos através da água, a poluição faz com que tenhamos dificuldade com isso ou até mesmo, confundimos o lixo com comida. Então, é importante que você cuido do ambiente onde vive, da natureza, porque outras pessoas dependem disso, se não pensarmos em cuidarmos um dos outros, tudo poderá acabar um dia, desde uma boa amizade até a Terra que vivemos. O amor é o principal ingrediente para cuidemos um dos outros e de tudo que existe!

Orienta-se aos professores nesta atividade que exibam este vídeo, caso não possua o dispositivo de mídia, que conte a história para os alunos, utilizando imagens que representem a história do vídeo. O vídeo possui legendas, em casos de alunos com surdez.

Link do vídeo: https://www.youtube.com/watch?v=OSJVStxV6TA

\section{MOMENTO 2:}

Após assistir ao vídeo, ou ao mesmo ser narrada, orienta-se ao professor que dê para os alunos um caça palavras "Peixes de água doce" com o conteúdo abordado, disponível também nesta sequência didática.

O Tempo aproximado para esta atividade é de uma a duas aulas.

\section{Atividade 2:}

Quantidade de aulas:4

Objetivos:

- Potencializar os conceitos abordados e os conteúdos científicos;

Conteúdo científico: Peixes - Vertebrados

Recursos: Computador, Televisão ou Datashow.

\section{Motivação:}

"Olá gente, vocês se lembram sobre o que falamos na aula passada? Onde encontramos os peixes? Vocês lembram da peixinha Jujuh? Como ela nasceu? Como é formado o corpo dos peixes? Como eles fazem para se movimentarem? E para respirar debaixo da água, vocês se lembram? O que acontece com o "xixi" do peixe? Vocês se lembram o que sai da urina dos peixes? Quem se alimenta disso? A poluição ajuda ou prejudica os peixes? O que devemos fazer?

Momento 1:

Esse momento é um momento interativo, orienta-se ao(a) Professor(a) que coloque os alunos em rodas, em volta do vídeo que será exibido. No primeiro momento, ao alunos estarão sentados em roda, acompanhando a música através da folha da música impressa. Em um segundo momento, o Professor(a) pede aos alunos que se levante e faz-se necessário que o professor(a) dance com os alunos e cante com eles a medida que o vídeo é reproduzido. Se possível, invente passos ou coreografias que represente as palavras do vídeo. Como por exemplo, quando falar de LAR, o professor faz o gesto de casa com as mãos. Use a Criatividade!

Link: https://www.youtube.com/watch?v=3ZXdMMG1PfE

Videoclipe da música “ÁGUA É O MEU LAR”, canal Semeando Cientistas.

Ative as legendas para Alunos com surdez ou veja a versão Remix, no link: 


\begin{tabular}{|c|c|}
\hline & $\begin{array}{l}\text { https://www.youtube.com/watch?v=YA3YOsbFhl0 } \\
\text { Esta atividade pode ser repetida em duas aulas a mais, pode-se aproveitar também para brincar com as } \\
\text { crianças de estátua, ou dança da cadeira com a música. } \\
\text { Momento 2: } \\
\text { Os alunos farão um origami de peixe e depois colocar na ordem exata do ciclo de vida dos peixes. } \\
\text { Origami de peixe, para ser elaborado com o auxílio da professora, do site Papelismo. Na dúvida, } \\
\text { acesse ao vídeo no link para compreender a dobradura: https://youtu.be/xlHokrVFMAY }\end{array}$ \\
\hline Aula 3: & $\begin{array}{l}\text { Atividade } 3 \\
\text { Quantidade de aulas: } 2 \text { aulas } \\
\text { Objetivos: } \\
\text { - Compreender conceitos sobre alimentação, morfologia e ciclo de vida biológico dos peixes. } \\
\text { Conteúdo científico: Peixes - Vertebrados } \\
\text { Recursos: massinha de modelar, lápis de cor. } \\
\text { Motivação: Vocês se lembram da música que ouvimos na outra aula? Sobre o que falamos? Quem } \\
\text { aqui sabe me dizer o que é um ciclo de vida? Vamos aprender? } \\
\text { Momento 1: } \\
\text { Nesse momentos, disponibiliza-se para os alunos massa de modelar ou biscuit (que também pode ser } \\
\text { feito com amido de milho e cola branca escolar), para que eles modelem de acordo com a imagem da } \\
\text { folha sulfite impressa com a imagem do CICLO DOS PEIXES. Caso não possua a massa de modelar, } \\
\text { peça para os alunos desenharem ou descreverem nos espaços correspondentes a figura abaixo. } \\
\quad \text { Uma dica: Pode se utilizar lantejoulas para imitar as escamados peixes, os ovos podem ser } \\
\text { feito de bolinhas de papel também. }\end{array}$ \\
\hline Aula 4: Finalização da SD & $\begin{array}{l}\text { Quantidade de aulas: } 2 \\
\text { Esta avaliação é uma dinâmica que pode ser dividida em grupos, equipes ou individual. Essa será uma } \\
\text { brincadeira conhecida como pescaria. O professor irá fazer os peixes de EVA, conforme vídeo } \\
\text { demonstrativo abaixo. } \\
\text { Link do vídeo: https://www.youtube.com/watch?v=heJq7SMF4zc } \\
\text { Após o professor ter feito os materiais, que podem ser com o auxílio doa alunos, fica a } \\
\text { critério do professor. Em cada peixe o professor deverá escrever as seguintes questões em cada peixe: } \\
\text { 1. Como nascem os peixes? R: De ovos } \\
\text { 2. Quando jovem, como se chamam os peixes? R: larvas ou larvinhas } \\
\text { 3. O que os peixes tem no corpo? R: Escamas } \\
\text { 4. Como os peixes fazem para se movimentar? R: Com Nadadeiras e barbatanas. } \\
\text { 5. Onde se encontra os peixes de água doce?R: Rios, lagos e lagoas. } \\
\text { 6. O que os peixes comem? R: plantas ou outros peixes. } \\
\text { 7. O que tem no xixi (urina) dos peixes? R: Amônia, Nitrato e Nitrito. } \\
\text { 8. O que as plantas fazem com o xixi dos peixes? R: se alimentam. } \\
\text { 9. Como é o ciclo de vida dos peixes? R: Ovo, larva, peixe, reprodução. } \\
\text { 10. Existem peixes que come outros peixes? R: Sim. } \\
\text { 11. O que prejudica a Natureza? R: ações negativas, poluição, lixo, etc. } \\
\text { 12. O que devemos fazer para Ter uma Terra linda? R: cuidar dela, ter amor, respeitar. } \\
\text { ponto. Se o professor quiser, poderá sortear algum prêmio que poderá ser dividido com todos os } \\
\text { alunos depois, como recompensa pela participação, como bala, chocolate, pirulitos ou algo que os } \\
\text { alunos gostem. }\end{array}$ \\
\hline
\end{tabular}

Fonte: Autores (2021). 
Além dessa SD desenvolvida para orientação do professor, foi desenvolvido um material didático para que aluno também pudesse fazer as atividades propostas pelo professor, que por sua vez possui uma aparência mais atraente que a do professor, cujo objetivo é atrair o interesse no aluno em interagir com o conteúdo e se motivem nas atividades pospostas. Esse material pode ser observado na Figura 1, apresenta-se colorido, com imagens ilustrativas, alegre, com todo o conteúdo abordado de modo a despertar o desejo do aluno no acesso ao material.

Figura 1 -Roteiro para os alunos como material complementar à SD de ictiologia.
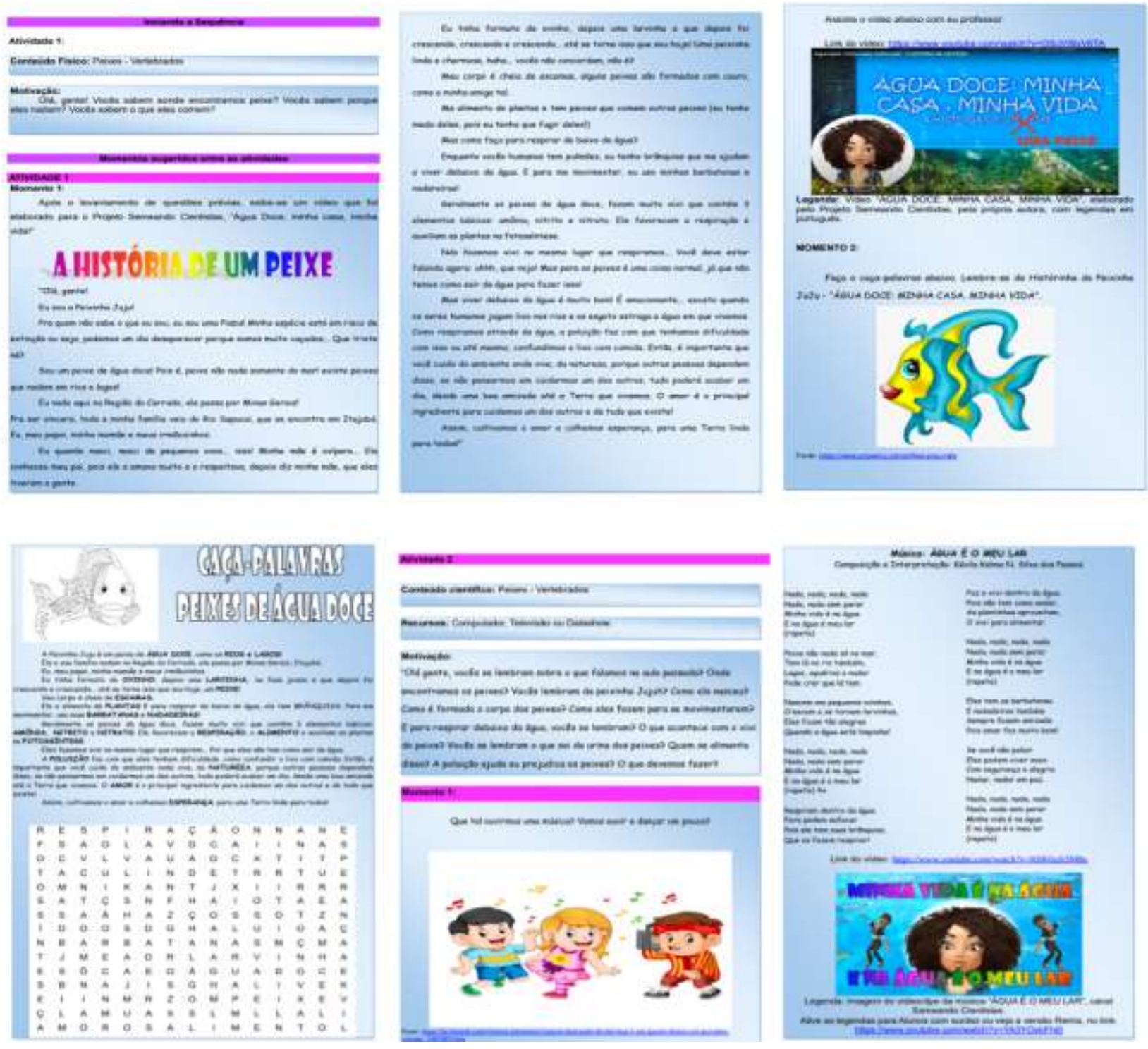

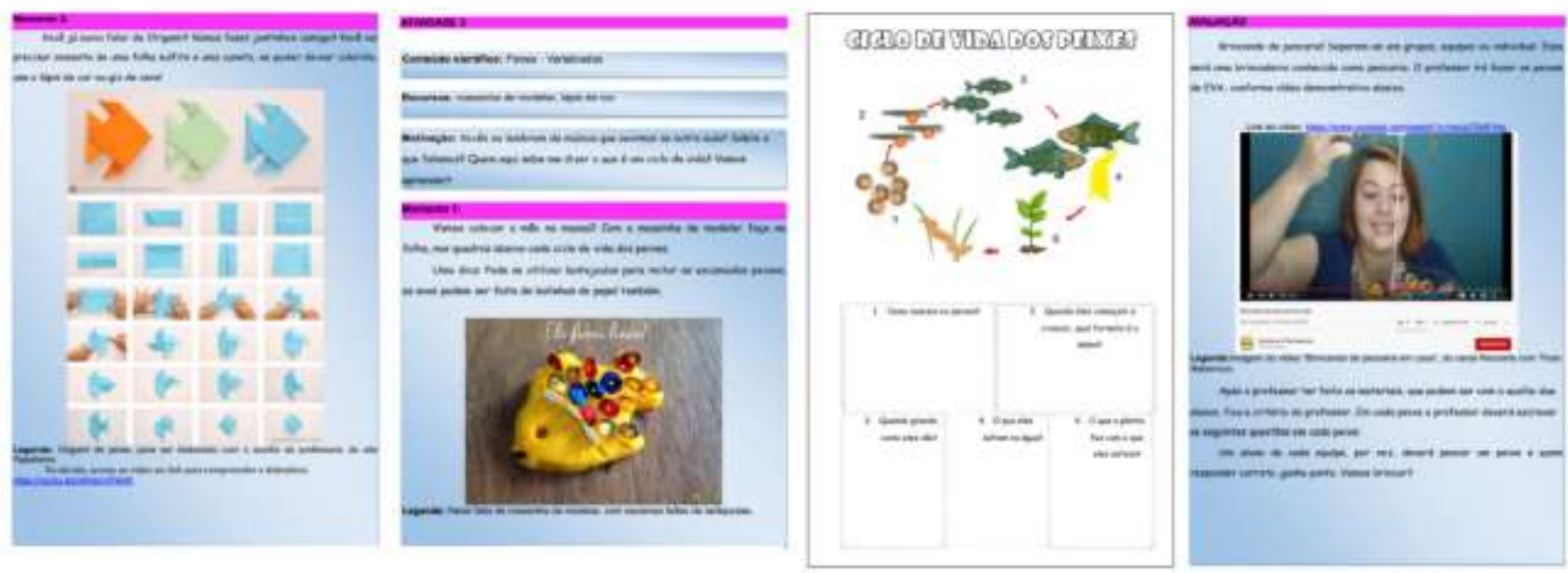

Fonte: Autores (2021).

\subsection{Análise da Sequência Didática}

\subsubsection{Metodologia CTSA e Competências da BNCC}

Analisando-se a Sequência Didática que foi desenvolvida, a qual é destinada a alunos com faixa etária de 9 a 10 anos, abrangendo os anos fundamentais iniciais 1, pode-se vislumbrar a apresentação do Tema “Água Doce Minha: Vida Minha Casa", uma analogia a um Programa Federal denominado "Minha Casa, Minha Vida", onde muitas famílias em vulnerabilidade socioeconômica tiveram a possibilidade de terem suas casas próprias. Principalmente, muitos alunos do Centro de Apoio, residem em bairros da cidade de Itajubá, cujas casas foram construídas por aquele, programa. Ao colocar esse título, teve-se por intenção que o aluno conseguisse correlacionar o tema à algo bom que aconteceu na vida de sua família, ao compreender esse título, tais alunos compreenderão o conceito de lar que conteúdo científico irá apresentar no decorrer da atividade.

Os recursos a serem utilizados são de fácil acesso, sendo eles: computador, folha sulfite, massa de modelar ou biscuit, folhas impressas, EVA, lápis de cor, lápis de escrita, televisão ou projetor multimídia. Durante toda a sequência didática existem sugestões de substituição, caso haja carência de tais recursos.

O conteúdo aborda especificamente a morfologia e a fisiologia dos vertebrados, sendo este conforme a BNCC, sobre a unidade temática Vida e Evolução, presentes no Quadro 1, anteriormente citado, bem como assuntos sobre respiração dos peixes, fecundação, reprodução e o ciclo de vida. A perspectiva do assunto é tratada de maneira bem lúdica e interessante, visto que tem como objetivo potencializar os conhecimentos prévios dos alunos, por meio de questionamentos, onde existe a secção "Motivação", onde o professor é orientado a fazer perguntas sobre os saberes trazidos pelos alunos, como por exemplo: O que você conhece sobre peixes?", "Peixe é encontrado somente no mar?” e após esse questionamento o aluno assiste a um vídeo, intitulado "A História de um peixe", que também pode ser narrado, caso não haja o recurso de projetor multimídia, computador ou qualquer outro recurso de vídeo.

A utilização de brincadeiras no decorrer da sequência didática é evidente, e isso colabora no desenvolvimento dos alunos, que acabaram de finalizar a educação infantil e o contribui para minimizar a falta de convivência social durante a pandemia. Kishimoto (2010, p.1) afirma que:

Para a criança, o brincar é a atividade principal do dia-a-dia. É importante porque dá a ela o poder de tomar decisões, expressar sentimentos e valores, conhecer a si, aos outros e o mundo, de repetir ações prazerosas, de partilhar, expressar sua individualidade e identidade por meio de diferentes linguagens, de usar o corpo, os sentidos, os movimentos, de solucionar problemas e criar. Ao brincar, a criança experimenta o poder de explorar o mundo dos objetos, das pessoas, da natureza e da cultura, para compreendê-lo e expressá-lo por meio de variadas linguagens. Mas 
é no plano da imaginação que o brincar se destaca pela mobilização dos significados. Enfim, sua importância se relaciona com a cultura da infância, que coloca a brincadeira como ferramenta para a criança se expressar, aprender e se desenvolver. (Kishimoto, 2010, p.1)

Essa relação do aluno com o objeto de aprendizagem, de maneira lúdica, promove e desenvolvimento social do aluno, a exploração de novos saberes do conhecimento científico da maneira pelo qual ele possui afinidade, aguça o interesse em sempre querer mais. Pires et. al (2018, p. 20) destaca a importância de atividades que promovam a aprendizagem significativa: “Dessa forma, compreende-se que o planejamento centrado na criança, em seus interesses e necessidades, garantirá ao/à professor/a segurança de estar proporcionando experiências significativas, nas quais a criança participa ativamente, de maneira autônoma, do processo de aprendizagem."

Para trabalhar a metodologia CTSA, a narrativa relata a história de um peixe chamada "peixinha Juju", que trata-se de uma espécie popularmente conhecida como Piaba, Hyphessobrycon coelestinus - um peixe de água doce e a espécie encontrase em risco de extinção (Ambiental, 2020), para abordar de maneira lúdica o conhecimento científico. A SD, então, aborda sobre o assunto crítico da ação do homem sobre o meio ambiente, que aliás, a história da espécie narrada, por conta da dessa extinção ela é caçada, e que tiveram que "mudar-se" da região de origem, por questões de sobrevivência. Narra também sobre como é o ciclo de vida do peixe, como no caso a reprodução, onde existe uma história de amor entre os pais, sobre o respeito que seu pai trata a sua mãe, destacando aqui a CTSA quanto à valores como respeito, bem como a BNCC (2018, p.566-569), além do Caderno de Educação em Direitos Humanos "educação deve afirmar valores e estimular ações que contribuam para a transformação da sociedade, tornando-a mais humana, socialmente justa e, também, voltada para a preservação da natureza" (Brasil, 2013).

Ademais, o vídeo retrata a morfologia do peixe, estrutura física e a respiração, do mesmo modo que, a fisiologia dos peixes. Neste ponto, para que o aluno compreenda sobre o assunto Aquaponia faz-se um adendo sobre as substâncias químicas, que auxiliam o processo deste sistema, sendo eles: Amônia, Nitrito e Nitrato. Eles por sua vez, favorecem a respiração na fotossíntese e a "nutrição" das plantas. Usa-se um vocabulário mais popular, quanto ao termo urinar, como a palavra "xixi”, sendo este mais infantil. Além de tudo, a narrativa ressalta sobre o prejuízo da poluição aos peixes, devido ao fato que eles respiram através da água, bem como a dificuldade que eles apresentam ao confundir o lixo com o alimento.

A história envolve também fatores emocionais e valores, como saber preservar amizades, sobre cuidar uns dos outros da mesma maneira, que deve-se cuidar do espaço em redor, da natureza, e do planeta em que vivemos: a Terra. Sugere-se valores morais, como a importância do amor ao citar que "o amor que é o principal ingrediente" para que que haja o cuidado com tudo que existe no decorrer da vida.

O professor, no decorrer da SD, é orientado a apresentar o vídeo elaborado para o desenvolvimento da aula. No entanto, caso ele não consiga ou não tenha recursos, ele pode contar a história ao alunos e utilizar as imagens existentes no vídeo, para que ele imprima e apresente aos alunos, atraindo o interesse dos mesmos.

Foi também pensado a prática inclusiva, para que promover que a maior parte dos estudantes tenham acesso ao conhecimento. Por isso, o uso de atividades manuais para incluir alunos com TEA, cegueira, entre outros) e todos os vídeos possuírem legendas incluindo alunos com problemas auditivos ou no caso de alunos apresentarem alguma dificuldade de compreensão do conteúdo, existem momentos práticos da atividade, para que eles "coloquem a mão na massa".

Posto ao fato, esta sequência didática contempla as quatro dimensões do modelo de estilo de aprendizagem de Felder \& Spurlin (2005, p.103-104), projetado para captar a diferença de estilo de aprendizagem, além das necessidades dos alunos, tal como a preferências por uma categoria, tais quais: Sensorial (pensador concreto, prático, orientado em direção a fatos e procedimentos), por exemplo, no momento em que se utiliza a massa de modelagem na SD; o Intuitivo (pensador abstrato, 
inovador, orientado para teorias e significados subjacentes), como quando, faz-se o uso das palavras-cruzadas e o ciclo dos peixes para que eles completem; o Visual (tem preferência por representações visuais do apresentado material, como fotos, diagramas, ou seja, preferem informações com demonstrações visuais), tal como, o uso de vídeos, imagens da história, animação gráfica na SD; Verbal (prefere a escrita e explicações faladas, explicações por meio da audição), como a utilização de música na SD; o Ativo (aprende por meio da experimentação e de trabalhos em equipes e aparenta extroversão) como a atividade "pescaria" apresentada na SD; o Reflexivo (aprende por meio do pensamento, da reflexão, cuja preferência é no trabalhar solitário ou com pessoas de sua afinidade, aparenta introversão), ao oferecer por meio da SD a oportunidade da Educação Ambiental, por meio da criticidade; o Sequencial (processo de pensamento linear, aprender em pequenas etapas incrementais), também comtemplada na SD nas palavras-cruzadas e o ciclo dos peixes; e por último, o Global (analítico, pensamento holístico processo, visual espacial), que envolve todos os processos da sequência didática, como a palavrascruzadas, a história, vídeos e músicas.

Todas as atividades são divididas em momentos. Uma aula, conforme pode-se verificar no Quadro1, pode ser dividida em vários momentos. Citando caso análogo, após a narrativa "História de um peixe", que se compõe o "Momento 1", da “Atividade 1", dá-se o prosseguimento para o "Momento 2" da "Atividade 1". Nesse momento, os alunos irão fazer um caçapalavras que contém palavras chaves do conteúdo que foi narrado através do vídeo. Pra que os alunos se acostumem aos novos termos científicos e também cotidianos, como as palavras: "AMÔNIA", "NITRITO", "NITRATO", "ÁGUA DOCE", "ESCAMAS", "RESPIRAÇÃO”, "ESPERANÇA", "NATUREZA”, entre outras. A intenção é que o aluno compreenda que o meio ambiente faz parte da vida dele, dos espaço da sua vivência, e que há a necessidade deste ser preservado. Nessa situação, envolve-se o aluno, ao fazer o uso da metodologia CTSA, quando pretende-se desenvolver no aluno uma criticidade, em que ele olha para o meio ambiente e analisa que a ação dele vai colaborar para preservação do meio ambiente, tal qual, seu futuro. Essas atividades podem ser repetidas mais de uma vez, por conta de ser uma sequência didática, de acordo com Antoni Zabala (1998), ao critério do professor que irá aplicar, e ser adaptada para o ambiente até que os alunos compreendam a história e fixem o conteúdo.

Na próxima etapa, atividade 2, levanta-se questionamentos aos alunos acerca dos conhecimentos desenvolvidos na aula anterior, como sobre a morfologia do peixe, "como eles se movimentam na água?", sobre "Quais os elementos básicos que eles liberam dentro da água?”, “O que acontece com os peixes quando há poluição?”. Após, esses questionamentos momento "Motivação" - a próxima etapa é o "Momento 1", que consiste em uma hora lúdica, como o uso de música: "Água é o meu Lar", do Projeto Semeando Cientistas, no canal do Youtube, na Figura 2. Tanto este vídeo quanto a "História de um Peixe" acompanham personagens 3D, que foram desenvolvidos para serem utilizados no Projeto. Inclusive, existe a recomendação para a ativação das legendas para alunos com surdez, além de uma versão Remix, que é o Lyrics vídeo. 
Figura 2 - Imagem dos do vídeo “Água é o meu Lar”, do canal Semeando Cientistas.

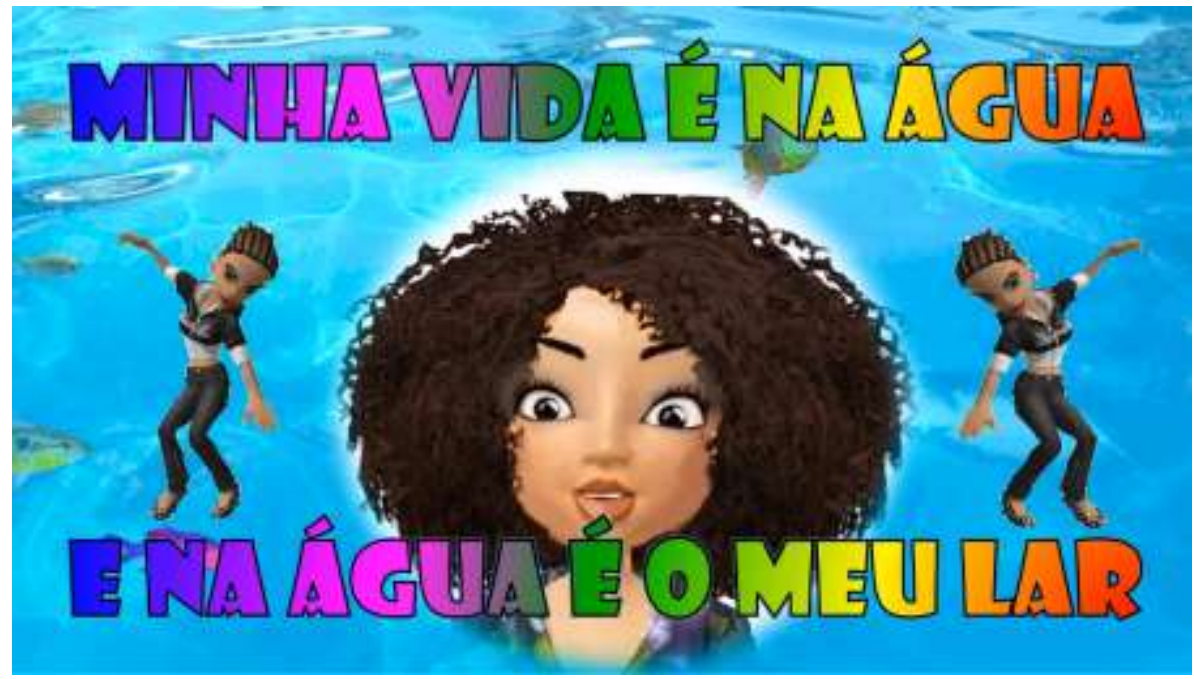

Fonte: https://www.youtube.com/watch?v=3ZXdMMG1PfE.

Para este momento caso não haja o projetor multimídia, o professor poderá utilizar apenas o efeito sonoro, provindos do celular, uma pequena caixa de som, televisão ou computador. O vídeo pode ser convertido em mp3 em sites de conversão online e assim, baixados em pendrive para reprodução em aparelho de som. Podemos observar que esta ocasião, é de interação entre professor e aluno, entre o educando e o educador. Orienta-se que o professor reúna com seus alunos em forma de roda, com sugestão de utilizar as danças ou coreografias com seus alunos, tal como: quando a música fala palavra "LAR", faz-se gesto com suas mãos em forma de "casa" e para assim, dançar juntamente com os alunos.

O uso da tecnologia também faz parte da abordagem CTSA, principalmente audiovisuais tendem a ser mais atraentes e facilitam no Ensino de Ciências. Em concordância, Lopes et. al (2021, p.13), relata “...trabalhos analisados reforçam as características instrumentalizadoras das tecnologias digitais no escopo do Ensino das Ciências da Natureza. Contudo, uma parte das produções, voltadas para a mediação através de mídias audiovisuais, estabelecem um diálogo mais profícuo com esse campo do saber."

Na sequência didática, a música "Água é o meu lar" foi desenvolvida recapitulando o assunto tratado na "História de um peixe", como assuntos sobre: a existência de peixes em água doce, não somente no ambiente marítimo; a importância da água na vida do peixe, para sua sobrevivência, para sua respiração através das brânquias; trata sobre como as plantas irão utilizar a urina desses peixes - para os conhecimentos futuros sobre Aquaponia. Faz-se significativo acentuar tais conceitos presentes nos sistema de Aquaponia, pois futuramente tais conceitos serão tratados em uma próxima sequência didática, a qual já foi desenvolvida, e será publicada futuramente. Então, o conceito a associação dos peixes e plantas, ganha destaque nessa música, os alunos compreendam, principalmente que, os elementos químicos liberados na urina dos peixes irão colaborar na nutrição e fotossíntese das plantas.

Trata-se também, aspectos críticos, outra vez falando sobre a relação entre a sociedade e o meio ambiente, como a frase da música “se você não for poluir, eles podem viver mais, com segurança e alegria, nadar, nadar em paz!”. Destaca-se a importância da conscientização dos alunos quanto à educação ambiental e sua ação sobre o meio ambiente. Orienta-se ao professor repetir quantas vezes forem necessárias, além da sugestão de aproveitar para poder brincar com seus alunos, como a dança da cadeira e estátua. Posteriormente, no "Momento 2" da "Atividade 2" é elaborada uma atividade criativa, em que os alunos vão produzir um peixe de origami para depois colocar na folha da sequência do ciclo de vida dos peixes. 
Estas atividades são mais simplificadas devido ao público-alvo em que a SD é destinada. Vejamos que são crianças cuja a faixa etária é de 9 a 10 anos, e a abordagem CTSA em que foi baseada, exige um pensamento crítico e argumentativo. Ante, a isso, pode-se estimular tais alunos ao pensamento consciente, promovendo a prática de ações que questionarão suas atitudes, além de toda a sociedade que o envolve. Nessa fase pedagógica, eles se encontram em formação de pensamentos, então resulta na facilidade de estimular o senso crítico, uma vez que o seu cognitivo está em uma fase avançada, conforme apontam Rodrigues \& Melchiori (2021, p.4):

... a criança em idade escolar está em uma fase de grande avanço cognitivo e com capacidade para compreender os conteúdos abordados em sala de aula. Ela apresenta também interesse em organizar coleções e está apta a participar de jogos com regras complexas. Todo esse processo é gradual, mas o ambiente deve oportunizar situações sistemáticas e organizadas para que isso aconteça. (Rodrigues \& Melchiori, 2021, p.4)

Para que a abordagem CTSA seja aplicada com eficácia, ela precisa favorecer mudanças que visam proporcionar benefícios para as pessoas, para a sociedade e para o meio ambiente, quando há uma apropriação do conhecimento científico pelo aluno. O que irá construir indivíduos capazes de argumentar quanto à descoberta de saberes científicos, sociais, tecnológicos, econômicos, culturais, e por fim, ambientais (Santos \& Silva, 2021, p.4).

As práticas e abordagens, como o pensamento crítico dos alunos sobre a poluição e de que outros seres vivos são prejudicados quando há interferência humana no ambiente, promove uma ação reflexiva nos alunos. Na abordagem CTSA, isso é possível mediante a essa promoção da conscientização e sensibilização acerca dos efeitos antrópicos sobre a natureza, ganhando notoriedade assuntos como a preservação do ambiente local e global e impulsiona os alunos a ações transformadoras de sua realidade local (Leal et. al, 2021).

Já na "Atividade 3", promove-se o momento "Motivação", com as seguintes perguntas: "Vocês se lembram da música da aula passada? Sobre o que falamos?", "O que o peixe faz?" para diagnosticar os conhecimentos adquiridos pelos alunos na aula anterior. Em continuidade, discorre-se sobre o ciclo de vida biológico dos peixes e entrega-se aos alunos massa de modelar, para que assim, eles façam os peixes de acordo com o ciclo de vida: ovo, larva, fase jovem, fase adulta e a interação com as plantas (necessário para o conhecimento sobre Aquaponia).

Depois que eles fizerem os peixes, na folha "Ciclo de Vida dos Peixes" - divide-se em quadros com as etapas 1, 2, 3, 4 e 5 , correspondentes a cada etapa do ciclo de vida, os alunos deverão colocar os peixes no ciclo exato representado na imagem: fase ovos, fase larval, fase jovem, fase adulta e por último, eles crescem -urinam e as "plantas vão se alimentar". Esta atividade é primordial para a compreensão futura sobre o conhecimento de Aquaponia, Piscicultura e Hidroponia, em que há associação da cultura de peixe e utiliza-se as águas para o cultivo das plantas. Neste instante, consolida o ensino e a aprendizagem científica quanto ao conteúdo que posteriormente será ministrado, o funcionamento do sistema de Aquaponia. Para tanto, o conteúdo da sequência didática aqui apresentada, pode ser trabalhado de maneira individual, independentemente da próxima SD, no desenvolvimento do assunto vertebrados sobre Ictiologia.

Por fim, realiza-se com os alunos uma avaliação dos conteúdos adquiridos no decorrer da sequência didática. E para que o aluno aplique o conhecimento, a avaliação é feita de maneira dinâmica, cujo o nome é uma brincadeira chamada PESCARIA. O professor fará peixes de EVA, conforme o link do vídeo disponibilizado. Após isso, ele vai escrever questões dentro do peixe e cada uma das questões serão sorteadas. Esta avaliação pode ser desenvolvida em duplas ou em equipes. É uma atividade que pode ser modificada e o professor pode adicionar questões que ele achar conveniente. Estas questões são sobre a morfologia, a reprodução, destaques sobre a educação ambiental e todos os assuntos científicos abordados durante a 
SD. Os alunos irão pescar a pergunta, um da dupla ou da equipe deverá responder e o aluno que acertar ganha uma premiação (bala, pirulito ou um brinde). Sendo assim, a avaliação será o resultado da aprendizagem dos alunos de modo formativo.

Vale ressaltar que em todos os momentos da sequência didática pretende-se colocar o que o aluno como um indivíduo ativo crítico sobre a sua ação do ser humano no meio ambiente para que sejam desenvolvido valores, conhecimentos e ações sobre a criticidade do aluno.

Mediante a essa experiência, Andrade \& Vasconcelos (2014, p. 8) quanto ao enfoque CTSA, avaliou-se que essa promove a participação ativa dos alunos em todas as etapas do trabalho, contribuindo à aprendizagem dos discentes e do professor, ante a sugestão de mais práticas que relacionem temáticas do cotidiano dos alunos como um facilitador do processo de construção do conhecimento.

\section{Conclusão}

Tendo em vista que a efetividade da abordagem CTSA no Ensino de Ciências, dependerá de como a toda a prática será aplicada. Foi desenvolvida uma sequência didática para auxiliar os professores, durante suas aulas para o conteúdo da BNCC de Ciências/ Biologia, tema "Vida e Evolução", visto que para uma abordagem CTSA faz-se necessário um bom planejamento por parte do docente e envolvimento e dos discentes.

O uso de tecnologias e metodologias ativas no decorrer da sequência didática torna-se atraente aos olhares dos alunos, visto que estamos em um período em que a tecnologia se tornou fundamental. E para isso, podemos aproveitar o máximo de desses recursos, já que em geral, estão disponíveis de maneira facilitada em nosso cotidiano.

Uma prática que permite novas experiências para os alunos, da educação Fundamental I, com ludicidade, poderá contribuir de forma positiva ao processo de ensino-aprendizagem.

A abordagem CTSA unida as competências da BNCC na sequência didática, resultarão na formação cidadã de indivíduos críticos, capazes de promoverem uma ação sustentável para preservação do meio ambiente, em uma sociedade harmoniosa, que respeita valores e as diferenças.

Esta pesquisa contribuirá para o desenvolvimento de práticas e ações docentes, em comunidades e em ambientes escolares em trabalhos futuros, bem como a sua aplicação no Projeto Semeando Cientistas com promoção da conscientização ambiental, o progresso social-emocional, interacional, pedagógico, tecnológico e econômico dos alunos.

\section{Referências}

Almeida, C. B. Da C., Garcia, A. R. S. De M., Sena, Denise Rocco De, Amado, M. V. \& Galleti, P. dos S. (2021). Aprendizagem Significativa Crítica No Ensino De Química: Contribuições De Uma Sequência Didática Numa Abordagem CTSA No Desenvolvimento De Percepções Sobre Drogas Inalantes. Experiências em Ensino de Ciências. 16 (2) 98.

Ambiental, Instituto Sócio. (2020). Coleção Eu Amo o Cerrado: peixes, aves, anfíbios, árvores, frutos comestíveis e mamíferos do Cerrado. https://acervo.socioambiental.org/acervo/documentos/colecao-eu-amo-o-cerrado-peixes-aves-anfibios-arvores-frutos-comestiveis-e

Andrade, B. dos S. \& Vasconcelos, C. A. de. (2014). O enfoque CTSA no Ensino Médio: um relato de experiência no ensino de Biologia. Scientia Plena, $10(4), 1-9$.

André, M. (2019). O que é um estudo de caso qualitativo em educação?. Revista da FAEEBA - Educação e Contemporaneidade, 22(40), 95-103.

Base Nacional Comum Curricular, BNCC. (2018). http://basenacionalcomum.mec.gov.br/images/BNCC_EI_EF_110518_versaofinal_site.pdf

Bacich, L. \& Moran, J. (org.). (2018) Metodologias ativas para uma educação inovadora: uma abordagem teórico-prática. São Paulo: Penso.

Brasil. (2013) Secretaria de Direitos Humanos da Presidência da República. Caderno de Educação em Direitos Humanos. Educação em Direitos Humanos: Diretrizes Nacionais. Brasília: Coordenação Geral de Educação em SDH/PR, Direitos Humanos, Secretaria Nacional de Promoção e Defesa dos Direitos Humanos.

Felder, R. M. \& Spurlin, J. (2005). Applications, reliability and validity of the index of learning styles. International Journal of Engineering Education, Ontario, 21(1), p. 103-112. 
Fernandes, I.M. B. \& Pires, D.M. (2019). Educação CTSA em Portugal. Uma análise das Metas Curriculares de Ciências Naturais. Revista CTS, s. 1., 14(40), 225-243.

Kishimoto, T. (2010). Brinquedos e brincadeiras na Educação Infantil. Anais do I Seminário nacional: Currículo em Movimento - perspectivas atuais. Belo Horizonte, 1.

Kurz, D. L., Bedin, E., \& Groenwald, C. L. O. (2020). O ensino de ciências: especificidades pedagógicas entre o dizer e o fazer. REAMEC - Rede Amazônica De Educação Em Ciências E Matemática, 8(3), 692-712.

Leal, J. F. P., Ribeiro, E. E. H., Costa, F. C. P. da, Costa, K. M. C. da, Nunes, J. M. \& Pimentel, W. L. (2021). Educação ambiental e abordagem em CTSA: estudo da potencialidade educacional de protótipo fotovoltaico em comunidade pesqueira. Revista Comunicação Universitária, Belém, PA, 1(1), 1-26.

Lopes, D., Alves, L. R. \& Lira-Da-Silva, R. M. (2021). O processo de instrumentalização no ensino de Ciências: uma revisão sobre o uso das tecnologias digitais. Revista De Ensino De Ciências E Matemática, 12(3), 1-26.

Maestrelli, S. \& Lorenzetti, L. (2021). A abordagem CTSA nos anos iniciais do ensino fundamental: contribuições para o exercício da cidadania. Revista Brasileira de Ensino de Ciências e Matemática, 4 (1), 18.

Minas Gerais. (2021). Secretária do Estado da Educação (SEE). RESOLUÇÃO SEE. $N^{o} \quad 4.506 / 2021.2021, \quad 2$. https://www2.educacao.mg.gov.br/images/documentos/4506-21-r\%20-\%20public.\%2026-02-21.pdf

Moro, L. G. B. \& Carlesso, J. P. P. (2020). Aplicação de uma sequência didática lúdica e interdisciplinar no desempenho escolar de alunos com dificuldades e distúrbios de aprendizagem. Kiri-Kerê - Pesquisa em Ensino, 1(9), 335-353.

Passos, K. K. N. S.(2020). Água é o meu lar - Projeto Semeando Cientistas. Youtube. https://www.youtube.com/watch?v=3ZXdMMG1PfE

Pereira A. S. et al. (2018). Metodologiada pesquisa científica. [free e-book]. SantaMaria/RS. Ed. UAB/NTE/UFSM.

Pires, A. R. De A., Coelho Neta, A. D., Brito, F. M. P. \& Martins, M. T. S. (2018). Caderno de orientações pedagógicas: educação infantil. Maranhão, Governo do Estado. Secretaria de Estado da Educação. São Luís. 9(2), 1 . https://www.educacao.ma.gov.br/files/2015/08/caderno-deEduca\%C3\%A7\%C3\%A3o-Infantil-completo-para-site.pdf

Prosas. (2021). Centro de Apoio Nossa Senhora do Sagrado Coração. https://prosas.com.br/empreendedores/25459.

Rodrigues, O. M. P. R. \& Melchiori, L. E. (2021). Aspectos do desenvolvimento na idade escolar e na adolescência. https://acervodigital.unesp.br/bitstream/unesp/155338/3/unesp-nead_reei1_ee_d06_s01_texto01.pdf

Santos, G., Miranda, S. \& De-Carvalho, P. (2021). Ludicidade \& ensino de ciências: oficinas pedagógicas enquanto ferramentas didáticas. Tecnia, 6(1), 178203.

Santos, W. J. Dos \& Silva I. P. da. (2021). Desenvolvimento e aplicação de uma proposta de ensino de ciências baseada no enfoque CTSA a partir de cenas do filme de ficção científica Avatar. Perspectiva, 39(2), 4.

Zabala, A. (1998). A Prática Educativa como Ensinar. Porto Alegre: ArtMe, 56. https://www.ifmg.edu.br/ribeiraodasneves/noticias/vem-ai-o-iii-ifmgdebate/zabala-a-pratica-educativa.pdf 